\title{
REGULATION OF FILTRATION CHARACTERISTICS OF HIGHLY WATERED TERRIGENOUS FORMATIONS USING COMPLEX CHEMICAL COMPOSITIONS BASED ON SURFACTANTS
}

\author{
Maxim Korolev, Mikhail Rogachev, Dmitry Tananykhin* \\ Saint-Petersburg Mining University, Russian Federation
}

A significant share of Russian oil fields has entered the final stage of development and is characterized by a drop in production. It comes true due to the depletion of active oil reserves, and, as a consequence, an increase in the proportion of residual oil trapped in areas which are not covered by flooding, and physically or chemically associated with the formation of oil. An additional factor is the increase in the water content of complex-structured terrigenous reservoirs and their high number of permeable intervals.

Development of the considered productive formations is carried out, as a rule, with maintenance of reservoir pressure by means of "cold" flooding. Despite the development and relatively low cost, it has its limitations/restrictions. The main reasons why we are not able to achieve complete displacement of oil by "cold" water are the difference between the viscosity of oil and the displacing agent, their immiscibility and hydrophobization of reservoir rocks [14].

All methods of enhanced oil recovery (EOR) used for highly watered oil fields with hard-to-recover reserves are aimed at additional recovery of residual oil and achieving the design oil recovery factor (ORF), by optimizing the flooding system and upgrading the flooding agents.

The design ORF can be achieved by increasing the water flood displacement efficiency, by improving the washing capacity of water (displacement agent), or by increasing the sweep efficiency of the reservoir flooding.

Key words: terrigenous formations, emulsions, heterogeneity, dynamic modeling, methods of enhanced oil recovery, change in filtrational flows

\section{INTRODUCTION}

There are lots of famous Russian and foreign specialists who has been investigated challenges of theoretical and applied aspects of EOR application: L.K. Altunina, G.A. Babalyan, Yu.P. Borisov, M.D. Valeev, V.E. Gavura, A.Sh. Gazizov, V.V. Devlikamov, R.N. Diyashev, Yu.P. Zheltov, R.R. Ibatullin, L.E. Lenchenkova, I.L. Markhasin,M.H. Musabirov, G.A. Orlov, M.K. Rogachev, N.M. Sarkisov, M.N. Sattarov,K.V. Strizhnev, M.L. Surguchev, A.G. Telin, R.S. Khisamov, I.A. Shvetsov, I.N. Shustef, S. Ali, K. Boney, M. Economides, H.S. Fogler, W.E. Kline, L. Lake, G. McLeod,C. Smith and others.

Despite some high rates of oil recovery factor, the development of a significant part of oil reservoirs in all countries of the world in terms of the completeness of oil reserves recovery is characterized as unsatisfactory. The solution of the problem of increasing the field development efficiency with residual oil reserves is associated with the creation of new and improvement of existing physical and chemical methods that provide a better recovery of oil and reduce the volume of associated water production.

\section{ANALYSIS OF MODERN EOR}

Let us consider the first group of methods, based on the increase in water flood displacement efficiency.

In oil production, a large number of chemicals (surfac- tants, alkalis, acids, etc.) are widely used, the main action of which is aimed at increasing the oil displacement efficiency.

The application of surfactants is based on improving the oil - washing properties of water by reducing the interfacial tension at the oil - water, oil-formation interface. The effect of using aqueous surfactant solutions is based on

2 mechanisms of surfactant action:

1. due to the reduction of surface tension, less energy is required to create a unit surface of the oil droplet, whereby the droplet is easily deformed and passes through pores of smaller diameter. Which leads to a decrease in pore pressures and a decrease in capillary forces;

2. washing effect of surfactant solutions is manifested in relation to the oil film covering the surface of the rock grains, which leads to rupture of the film and dispersion of oil in the aqueous phase $[4,8,12,29$, 31].

Field experiments and laboratory studies presented by $[3,6,15,19,20,22,27,36,45]$ was found that one of the most effective EOR technologies are physico-chemical methods based on injection a water with the addition of surfactants or mixtures into the formation. The interest of researchers in the study of physical and chemical properties of surfactant-based compositions is caused by synergistic effects (increase in surface activity, decrease in the critical concentration of myceliation, change in 
the rheology of the solution) observed during laboratory studies and their high technological efficiency during implementation at the field.

A positive result was shown by numerous laboratory studies of the physicochemical, rheological properties of ionogenic and non-ionogenic surfactants together with filtration experiments. Confirmation of laboratory studies was obtained during experimental and field work on the reservoirs of Bashkortostan and Tatarstan Republics [2, 3, 16, 29, 32].

To assess the degree of additional oil displacement efficiency from the reservoir is obtained by carrying out pilot testing of nonionic surfactants on Romashkinskoye oil field. In one section of the reservoir, the increase in oil production amounted to 18 thousand tons, or $14 \%$ compared to the design production. In the second section of the resevoir after 4 years of injection of $0.025 \%$ surfactant solution in two sections, the amount of production was 42.8 thousand tons of oil, or 73 tons of oil per 1 ton of injected surfactant.

The efficiency of the mentioned above technologies decreases with the increase of water cut. Therefore, the volume of their application in the 90th decreased, because most of the oilfields are at the final stage of development during this period, characterized by a slow decline in oil production and an increase in the water cut of the overall production of wells to $95-98 \%$ (the limit of profitability of well operation). Currently, flooding with surfactant is practically not implemented. As a rule, a combined surfactant-polymer effect is used [40, 42, 44, 45, 46, 51, 52, 53].

As noted by the authors of the work [33], despite the positive impact of surfactant during reservoir flooding on the current oil recovery and reduction of water production, according to field data, it is difficult to assess the efficiency unambiguously, since the increase in the oil recovery factor does not exceed $2-5 \%$, which indicates the limited possibilities of enhanced oil recovery enhancement methods based only on the principle of reducing interfacial tension.

Now let's consider the second group of methods based on increasing the sweep efficiency.

The use of polymer flooding contributes to an increase in the sweep efficiency of the reservoir flooding by reducing the ratio of water and oil mobility due to an increase in the viscosity of the injected oil displacing agent.

This mechanism is evident because of the polymer adsorption in a porous medium during filtration of a polymer solution, leading to decrease permeability of porous media on water even after complete exclusion from them of the polymer solution as the polymer macromolecule, as polyelectrolytes (polyacrylamide), swell in water and increase in size with the formation of inactive hydrated shell. On the mobility of oil macromolecules of polyacrylamide actually do not affect since oil consists mainly of non-polar molecules.
Polymer flooding has been used for more than 40 years. During this time, many projects have been implemented in various geological and physical conditions [1, 6, 8, 29, $37,41,48,49,51,57]$.

In the 90thof the last century, the undisputed leader in the field of polymer flooding was the United States - in 1986, 178 projects were implemented there. However, the decline in oil prices, as well as new developments that have allowed to solve the technological problems of using gas methods, significantly reduced the number of polymer flooding projects.

Now the leader in the field of polymer injection is China. Polymer flooding is successfully applied in the main fields of China, such as Daqing and Shengli. The use of polymer flooding only in these two fields allowed to obtain in 2004 about 14 million tons of oil, an increase in ORF of $14 \%$ was obtained.

Twenty years of successful field experience in the application of polymer flooding in China has shown that it can be effectively used in fields with water content above $95 \%$, giving an increase in ORF up to $10 \%$. It is established that polymers with a molecular weight of 10 to 18 million can be used in most reservoirs, polymers with a higher molecular weight are more effective in high-permeable reservoirs, salt-resistant polymers with a low molecular weight - in low-permeable reservoirs.

As for the Russian Federation, one of the commercially available water-soluble polymers that have passed largescale tests in the practice of oil production are various brands of polyacrylamide (PAA) [16, 28, 33]. At a concentration of polyacrylamide in a solution of $0.01-0.1 \%$, its viscosity increases to $3-5 \mathrm{mPa}$ *, which leads to the same decrease in the ratio of oil and water viscosities in the formation.

However, this method has major drawbacks that limit its wide application. As shown in the works [7, 8, 20, 33], the main disadvantages of polymer flooding are:

1. a sharp decrease in the intake capacity of injection wells due to an increase in apparent viscosity due to the destruction of polymer molecules in bottom-hole zones;

2. it is ineffective in homogeneous formations containing low viscosity oil (less than $5.0 \mathrm{mPa}^{*} \mathrm{~s}$ );

3. low efficiency of implementation at the final stage of reservoir development with water cut of more than $70 \%$, due to the formation of extensive washed zones in the reservoir;

4. efficiency of polymer flooding decreases with an increase in permeability of more than $1.5-2.0 \mathrm{mkm}^{2}$.

The use of polymers, polymer-disperse systems, colloidal-dispersion systems allow to increase the drainage layer by increasing fluid flow resistance in areas of flooded oil reservoir. At the same time, water tends to pass into areas not previously covered by flooding $[1,6,8$, $29,35,47,50]$. Colloidal gels are used as option of polymer flooding, in which the rim is reduced to $10000 \mathrm{~m}^{3}$ and 
below. One option is the BrightWater (Nalco) technology, which is based on the injection of dispersion of ultra-small polymer particles that swell and cross-link after placement in highly permeable water-saturated layers/ rims in reservoirs with high temperature [34, 38, 56].

Thus, modern research is focused on searching more effective surfactants or their compositions, as well as on optimization of chemical reagents injection methods into the formation, i.e. implementation of new complex technologies (surfactant-polymer, surfactant-polymer-alkaline flooding, micellar flooding, etc.). According to scientists, the application of technologies with complex action will increase the sweep efficiency of the reservoir flooding and at the same time increase the water flood displacement efficiency.

\section{PREREQUISITES FOR RESEARCH}

Most of the up-to-date methods of increasing oil recovery are based on flow-deflecting technologies, technologies of limiting water production and leveling the profile of injection wells, which allow to achieve effective oil recovery at a final stage of a field development.

Currently, sludge-and gel-forming compositions are widely used for selective isolation of water-saturated intervals, but they have disadvantages too. The main one is that the structure of these compounds is almost irreversible. At the same time, part of the oil reserves of the field remains in the isolated area, although it's small, which after isolation becomes almost impossible to be recovered. Since the restoration of the poroperm properties of the interval isolated by such compositions is a rather labor-intensive process, these technologies reduce the final oil recovery factor.

Therefore, technologies that allow to temporarily limit or block filtration on highly permeable areas are becoming more and more relevant [8]. Reverse emulsions with the addition of surfactants are a promising type of compositions that allow to solve this problem. Today they are used in drilling $[11,25]$ and oil field practice $[10,21,23$, 26], including to increase oil recovery in order to align the displacement front $[5,9,13,60,57,38,43,54,55]$.

They are a thermodynamically unstable dispersion system, the dispersion medium of which is oil and the dispersed phase is water [24, 30]. In this case, the emulsion structure has sufficient rheological properties for selective isolation of watered intervals. Since the dispersion system is unstable in formation conditions, the isolation of well-permeable interlayers is temporary, and after the destruction of the structure of the composition, the adsorption of surface-active components of the emulsion allows hydrophobizing the surface of the pore channels of the formation. Due to this, the phase permeability of the water decreases and the oil-washing capacity of the injected agent increases.

This leads to the redistribution of filtration flows and the inclusion in the work of previously idle intervals of the formation and additional recovery of residual oil using this technology.
Literatureanalysis contains data on laboratory studies and the experience of field tests of new compositions. It shows that for fields with a long period of impact on the reservoir by water injection, the most promising methods of increasing oil recovery will be physico-chemical or new combined methods based on chemical compositions. Injection of surfactant-polymer mixtures, microemulsions or micellar solutions will solve problems arising at the final stage of development of highly watered reservoirs. And the main purpose of the application of complex technologies of physico-chemical reservoir stimulation is to achieve design ORF due to the simultaneous increase of the water flood displacement efficiency and increase the sweep efficiency[17].

\section{RESEARCH PLAN}

Authors have developed an emulsion composition with hydrophobic properties based on reservoir water and kerosene (TS-1), emulsifier of which is YALAN-E2, with the addition of functional components: anionic surfactant (sulfonol) and complex surfactant (hydrophobizer NG-1). The proposed composition is acceptable for the technology of leveling the displacement front within the inhomogeneous permeability objects.

According to the data obtained during the laboratory studies of the developed composition, hydrodynamic models were simulated wtithin three approximations:

1. A simple model of a linear section of a layered-inhomogeneous formation consisting of two interlayers of equal capacities and different permeability.

2. A complex model of a linear section of a layered-inhomogeneous formation consisting of 10 interlayers of different capacities, permeability and water saturation.

3. A hydrodynamic model of the reservoir (section of the reservoir), adapted to the current field indicators of development.

\section{RESULTS OF HYDRODYNAMIC SIMULATING ON A SIMPLE MODEL OF A LAYERED-INHOMOGENEOUS RESERVOIR}

The model was a layered-inhomogeneous layer with lithologic-facies and poroperm properties similar to the upper Devonian layers (Figure 1). The properties of the fluids saturating the reservoir were also taken from studies of oil and reservoir water of the fields under consideration.

Interlayers with the permeability of the lower $0.120 \mathrm{mkm}^{2}$ and the ratio of permeability of the lower to the upper interlayer, equal to $1: 1,1: 3,1: 5,1: 7$ and 1:10 were selected to the further experiments.

In one case, the reservoir was flooded without the use of special agents, the simulation of the model was carried out until the water cut of the produced products was equal to $96 \%$.

In the simulation of oil recovery using the developed re 


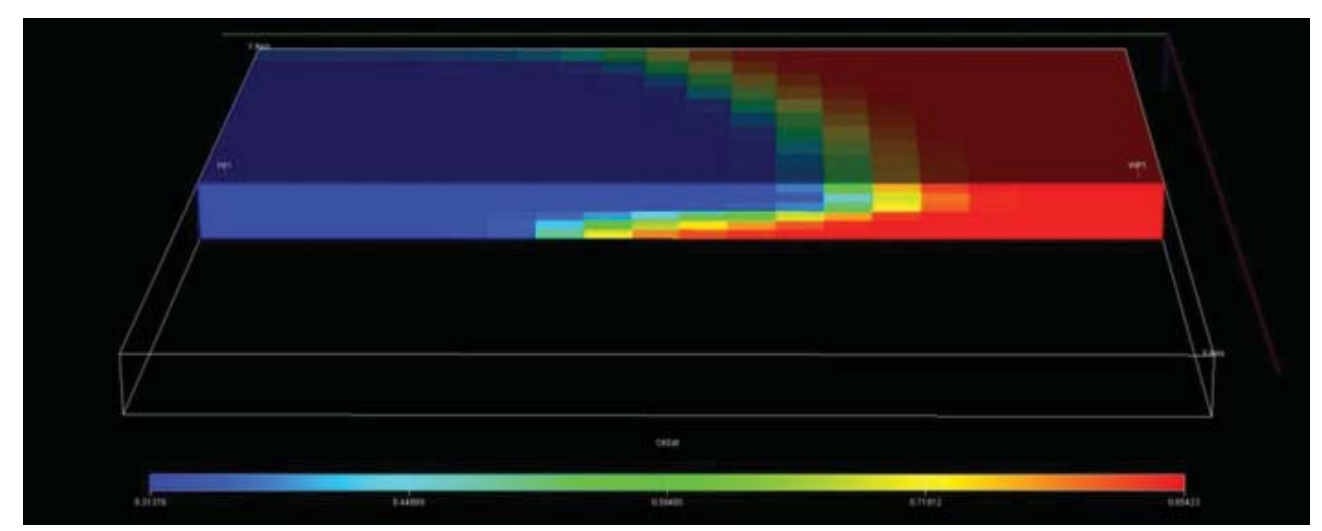

Figure 1: The developed model of flooding of layered-inhomogeneous reservoir

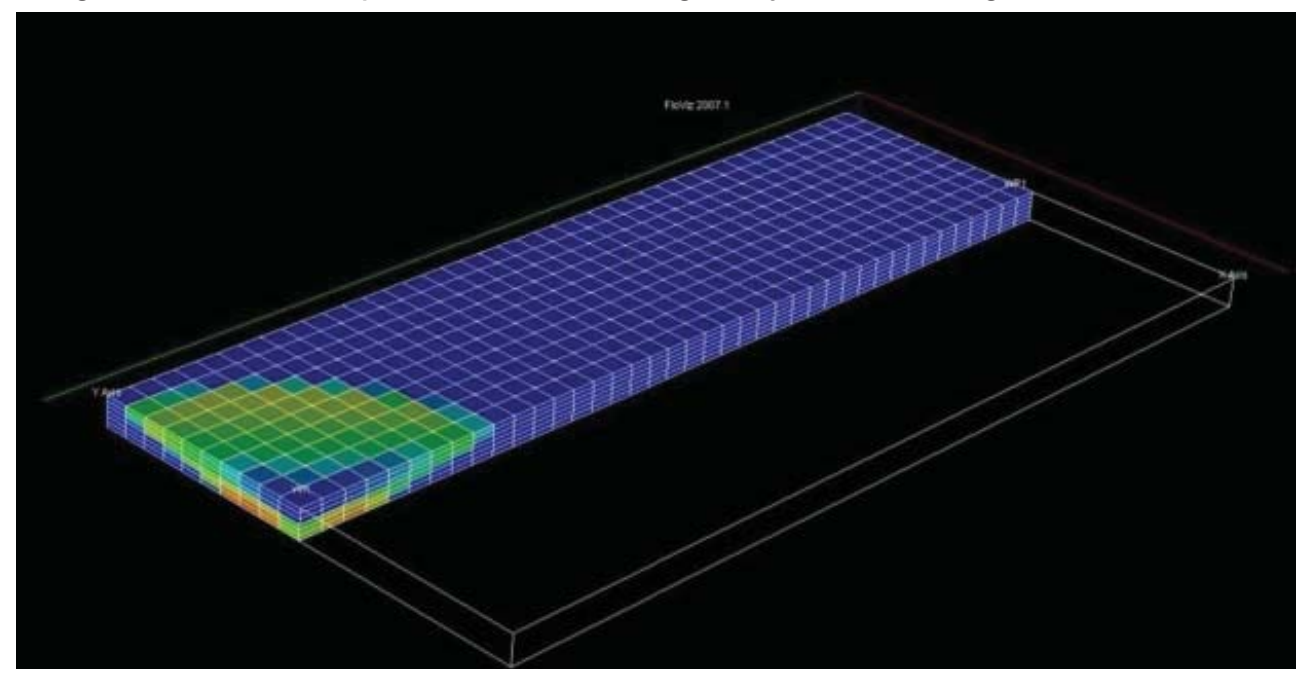

Figure 2: Simulation of the injection of the emulsion rim

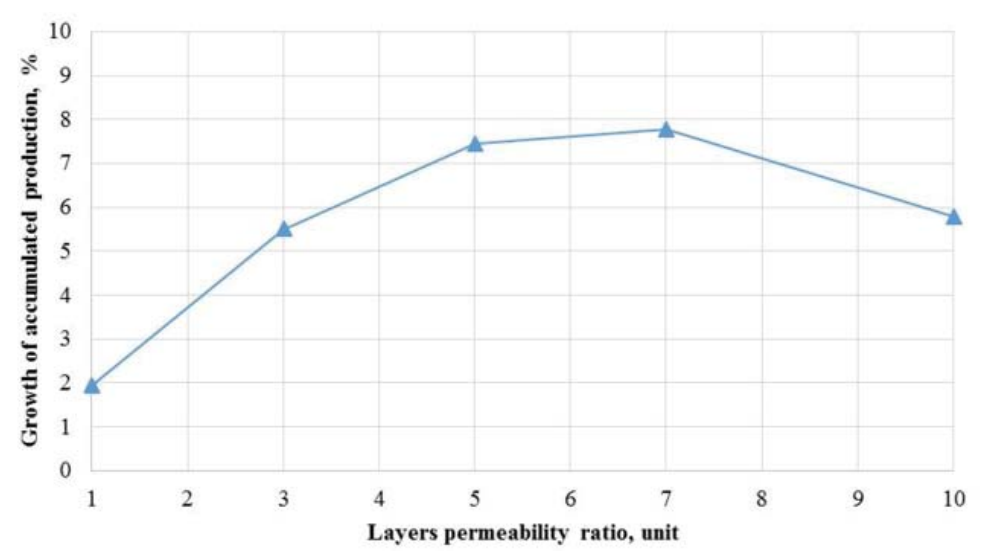

Figure 3: Dependence of the increase in accumulated production on the degree of heterogeneity of the reservoir

Table 1: Values of final oil recovery factor (ORF) at flooding of models with a different degree of in homogeneity

\begin{tabular}{|c|c|c|c|}
\hline \multirow[b]{2}{*}{$\begin{array}{l}\text { The ratio of } \\
\text { permeabili- } \\
\text { ties }\end{array}$} & \multicolumn{2}{|l|}{ ORF, unit } & \multirow[b]{2}{*}{$\begin{array}{l}\text { The in- } \\
\text { crease of } \\
\text { ORF, } \%\end{array}$} \\
\hline & $\begin{array}{l}\text { Flooding without the applica- } \\
\text { tion of the technology of the } \\
\text { emulsion injection }\end{array}$ & $\begin{array}{l}\text { Water flooding with appli- } \\
\text { cation of technology of the } \\
\text { emulsion injection }\end{array}$ & \\
\hline 1 & 0,673 & 0,686 & 1,9 \\
\hline 3 & 0,631 & 0,666 & 5,5 \\
\hline 5 & 0,618 & 0,664 & 7,4 \\
\hline 7 & 0,602 & 0,649 & 7,8 \\
\hline 10 & 0,588 & 0,622 & 5,7 \\
\hline
\end{tabular}




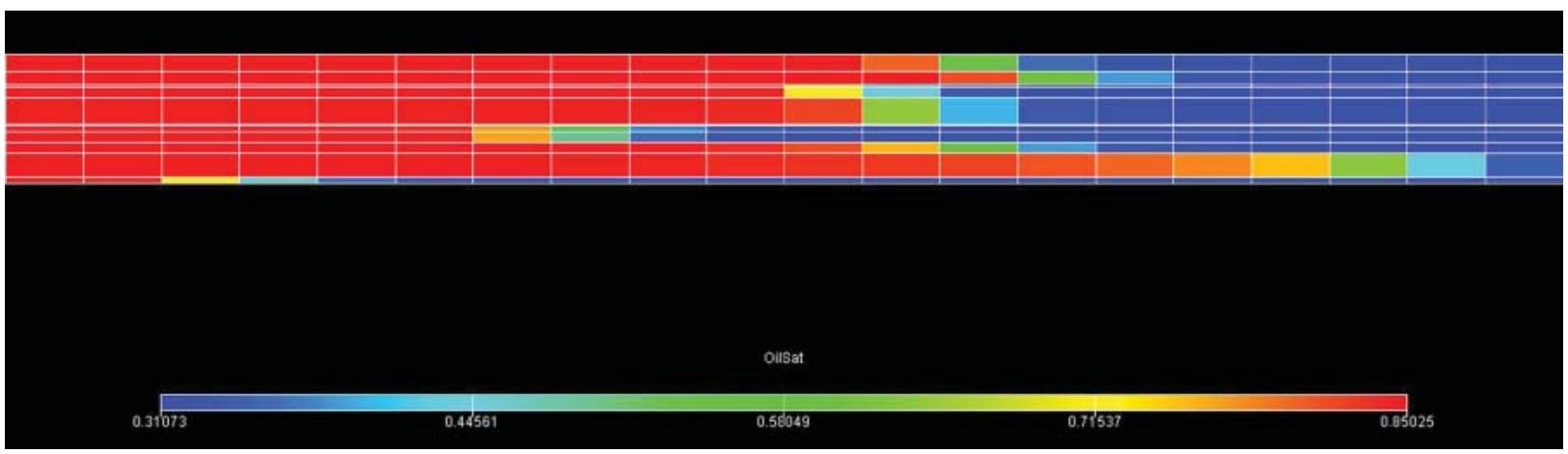

Figure 4: Displacement front on the model of layered-inhomogeneous reservoir according to the first simulation option

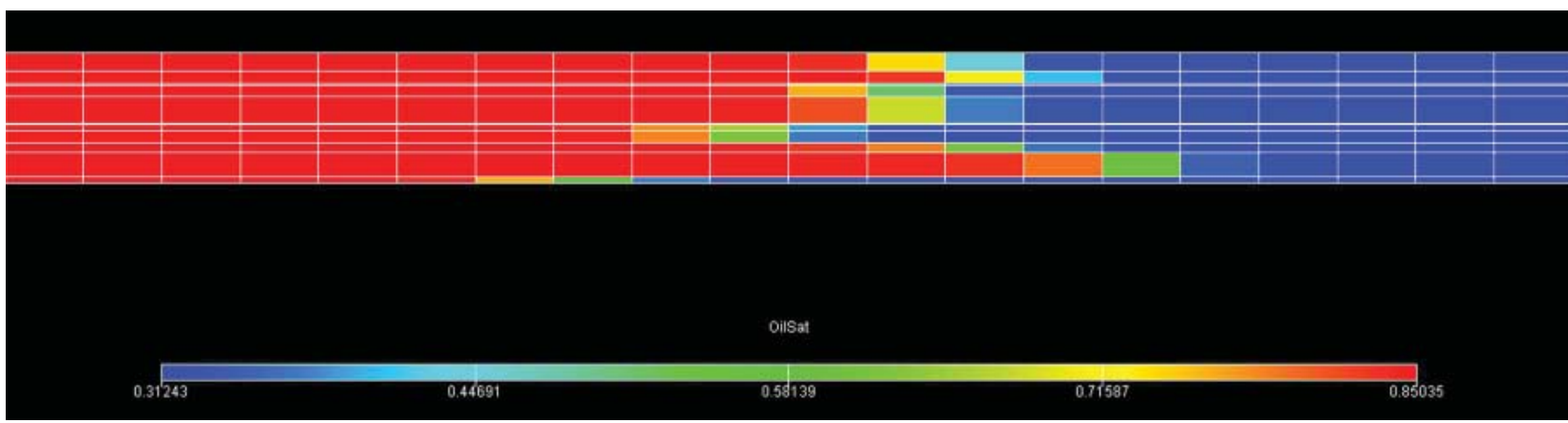

Figure 5: Displacement front on the model of layered-inhomogeneous reservoir according to the second simulation option

verse emulsion, the reservoir was first flooded without the use of agents until the water content of the produced products was $85 \%$, then the emulsion rim was pumped for 100 days (Figure 2). Further flooding was carried out, as in the first case, to the water cut up to $96 \%$.

Results of laboratory studies and 3D hydrodynamic simulations determined the optimal conditions of applicability of the developed technology, as the degree of inhomogeneity of the object and the maximum value of reservoir permeability [18].

It is important to note that according to laboratory filtration studies, close to the reservoir conditions, the developed emulsion composition has stability in reservoir conditions and does not break down when interacting with reservoir water. Also, the emulsion composition has selectivity and can be recommended for use in conditions of significant heterogeneity.

However, when simulating a hydrodynamic model with a layered-inhomogeneous formation, the lower limit of permeability was set as constant, and only the upper limit was changed. Due to the high permeability of the upper interlayer, the emulsion screen breaks, which is reflected in the results (the efficiency drop during the simulation is $1: 10$ (Table 1, Figure 3 )). Stability criteria for emulsions in the reservoir were developed based on rheological studies of emulsions and laboratory filtration experiments.Results of these experiments showed that we can recommend this technology for implementing within the permeability of flooded reservoir not more than $0,6-0,8 \mathrm{mkm}^{2}$, which corresponds to conditions of the object.
That is, it can be argued that the use of the technology is recommended for a difference in permeability of more than 5 times, but, at the same time, the most permeable interlayer should have a permeability of not more than $0.6-0.8 \mathrm{mkm}^{2}$ to retain the emulsion rim in the formation.

\section{RESULTS OF HYDRODYNAMIC SIMULATING ON A COMPLEX MODEL OF A LAYERED-INHOMOGE- NEOUS RESERVOIR}

Authors decided to investigate the impact of geological and physical characteristics of layer-by-layer heterogeneity on the effectiveness of the technology of displacement front alignment with the use of emulsion composition [18] after providing studies of the oil displacement on the simplest hydrodynamic model.

To solve this challenge, a model of the productive layer (represented by 11 layers) was simulated. The condition of vertical equilibrium of pressure is fulfilled. The thickness of the net pay zone is $33.2 \mathrm{~m}$; distribution of the permeability is random, without any regularities. Residual oil saturation is 0.27 unit, the formation oil volume factor is $1.475 \mathrm{~m}^{3} / \mathrm{m}^{3}$, water $-1.103 \mathrm{~m}^{3} / \mathrm{m}^{3}$. Viscosities of water and oil correspond to viscosities of the considered geological objects $-0,5 \mathrm{mPa}{ }^{*}$ s and $5 \mathrm{mPa}^{*}$ s respectively. Geometric dimensions of the linear section of the reservoir: width $-300 \mathrm{~m}$, length $-1500 \mathrm{~m}$. The properties of the emulsion are determined on the basis of physico-chemical and rheological laboratory studies.

Figure 4 shows the moment of the onset of advanced flooding, namely the water breakthrough on one of the 
interlayers. In turn, figure 5 already shows the advance of the front in the second option of the simulation (flooding with edging emulsion). The effect of the displacement front alignment after injection of the emulsion rim is obvious from the comparison of figures 4 and 5 , due to slow migration of the water through the highly permeable layers (on the same date the front in a second option of flooding smoother).

\section{THE RESULTS OF HYDRODYNAMIC SIMULATING ON THE RESERVOIR MODEL IN CONDITIONS CLOSE TO THE OIL FIELD}

Laboratory studies of the developed emulsion composition on the physical model of the layers showed that after it's filtration through the layer, it increases the filtration resistance just for water-saturated interval, thereby further filtering the water phase is slowing down.

In this regard, it can be argued that the use of the developed technology for regulating filtration flows in hetero-

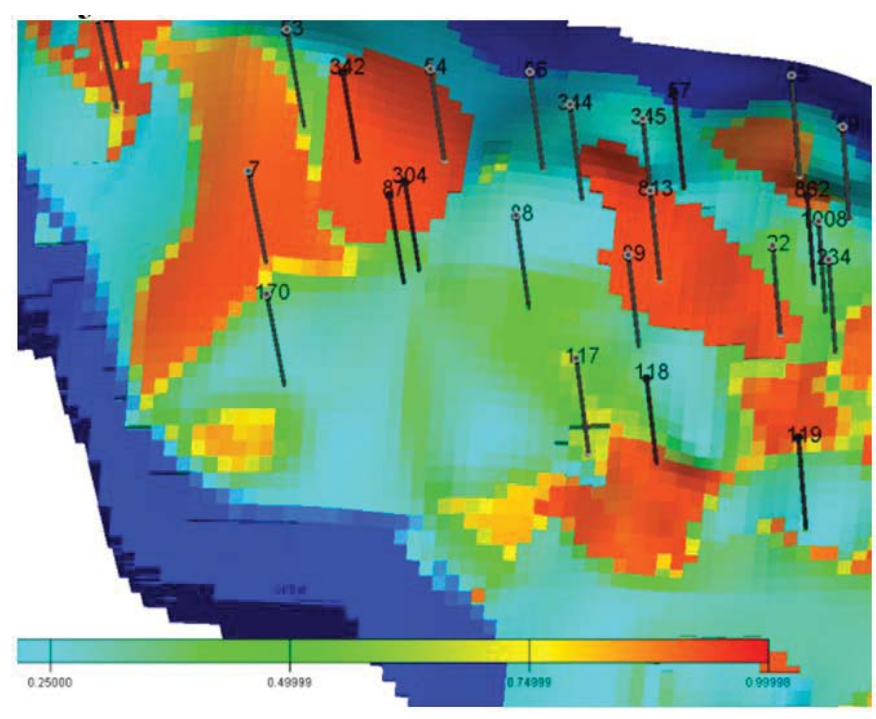

Figure 6: Fragment of the map with the initial oil-saturated thicknesses of section No. 1 of field No. 1.

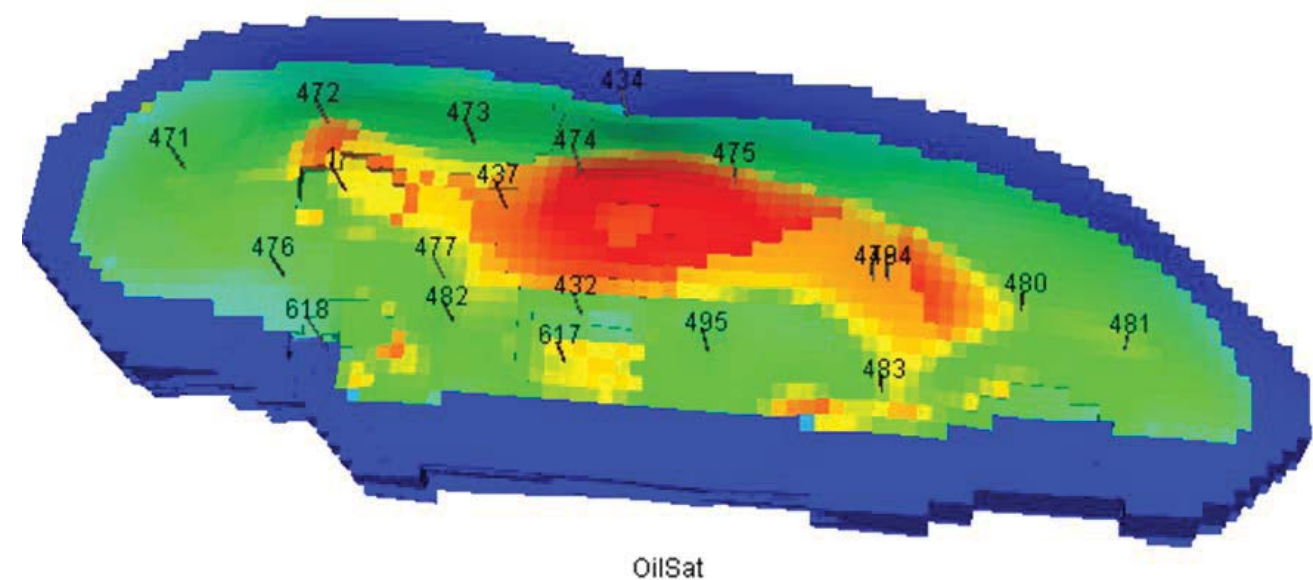

OilSat

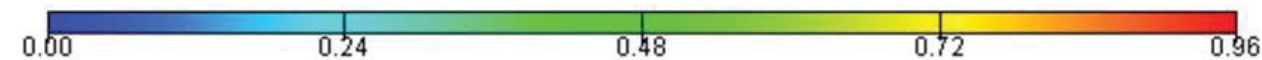

Figure 7: Fragment of the map with initial oil-saturated thicknesses of field No. 2.

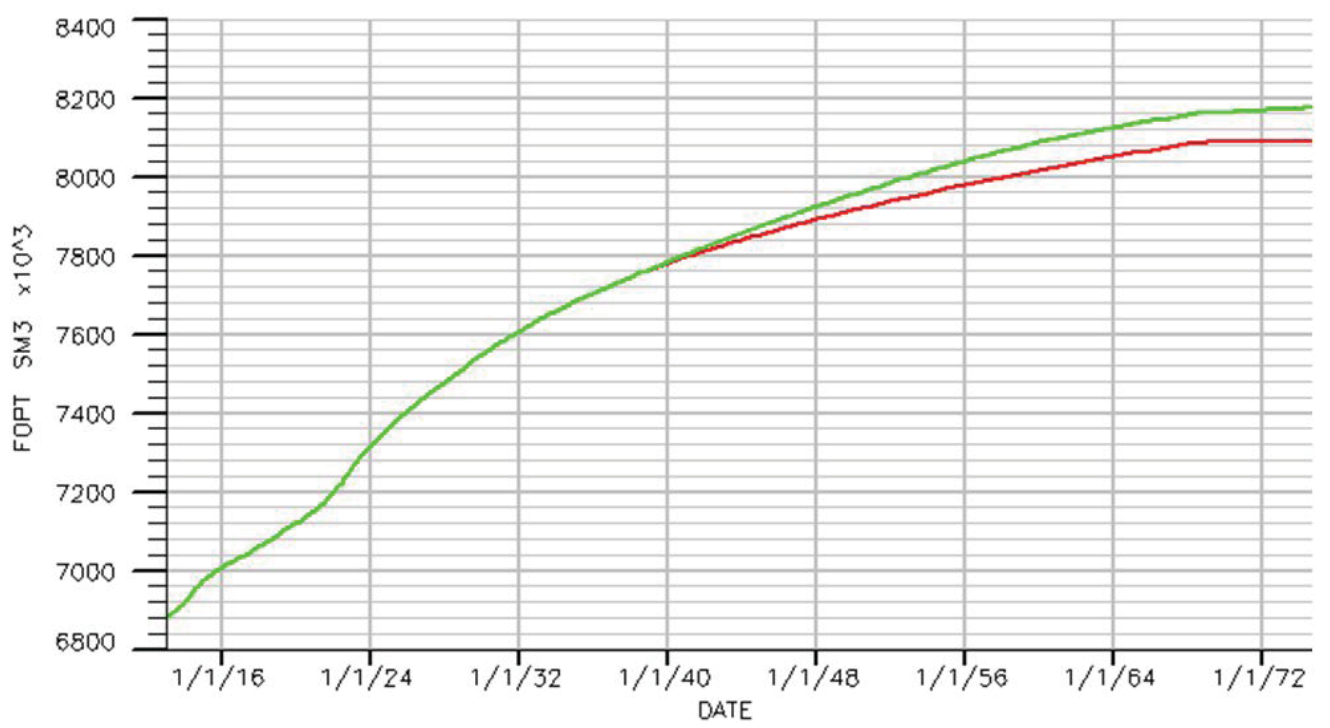

Figure 8: Accumulated oil production by years of development (red line - basic option, green line - option with the application of the considered technology) 


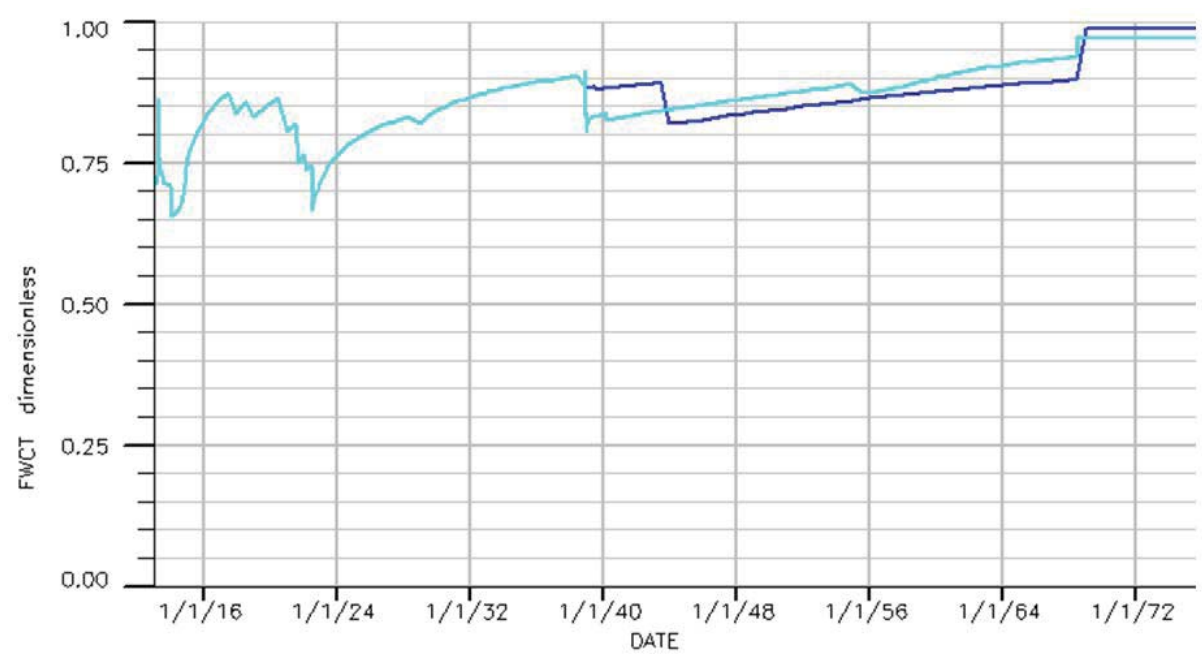

Figure 9: Water cut of the layers (blue line is a base option, pale-blue line is an alternative with application of the technology)

geneous terrigenous oil reservoirs will align the front of oil displacement by water and, as a consequence, will increase the efficiency of oil recovery from highly watered terrigenous reservoirs due to additional extraction of oil from previously involved areas in the development.

According to the data obtained in the laboratory studies of the developed composition, hydrodynamic models of flooding at two objects were simulated [18]. Two reservoirs of the Samara region were considered, the first one was a section of a large development object, and the second one was a whole multi-layer development object, since the reservoir is average in reserves. At each of the considered objects some wells were selected in the areas with weakly drained interlayers (Figures 6 and 7). The effect of the technology was evaluated: at the first site for three production wells per injection well; at the second site as a whole for the operation of five injection wells.

The lithologic-facies and poroperm properties of the models are similar to those of the upper Devonian and lower Carboniferous strata. The properties of the fluids saturating the reservoir were taken from studies of oil and reservoir water of the oil fields. The simulated reservoirs are at a final stage of development. The degree of depletion at these sites is about $85 \%$ of the recoverable reserves.

As an example, let's consider the results of hydrodynamic simulating of the considered multilayer object of the field No. 2 in two design forms: without the use of technology alignment displacement front (for project development) and with the injection of the composition. According to the second option, the developed emulsion composition was pumped into injection wells for a month with a flow rate of $100 \mathrm{t} /$ day per well. At the same time, the total volume of injection was -15500 thousand tons. After that, the composition was forced into the formation of the previously pumped water of the reservoir pressure maintenance system $[61 ; 62]$.

Evaluation of the efficiency of the considered technolo- gy was evaluated according to the accumulated production for the years of development, as well as the change in the average water cut. The results are presented in graphs (Figure 8-9). The graphs show that after the start of injection of the developed emulsion composition, we get a decrease in water cut by $10 \%$, and an increase in oil production from the first year of implementation of the technology. Additional production at the facility amounted to 35,368 tons of oil over 10 years. Accordingly, we can consider the effect of the application of technology about 0.7 thousand tons per well operation per year.

It was also noted that the reduction of water cut achieved by involving in the work of previously not covered by flooding areas of interlayers. Additional production was about $2 \%$ at both sites, which indicates a good correlation of the efficiency of the developed emulsion composition.

\section{CONCLUSION}

Thus, the results of the research allowed to draw the following conclusions:

1. Features of the terrigenous reservoirs development at the final stage are high lithological heterogeneity of the layers containing the main oil reserves, and advanced flooding of highly permeable interlayers or one layer in a multi-layer object, which leads to uneven development of reserves in the area. Therefore, technologies that allow to temporarily limit or block filtration in high-permeable areas are becoming more and more relevant.

2. The developed reverse emulsion is applicable for the technology of leveling (alignment) of the displacement front of inhomogeneous permeability objects.

3. The dependence of the possible achievement degree of the oil recovery factor using the developed emulsion on the degree of the terrigenous formation heterogeneity is established.

4. The implementation of the developed technology of 
filtration flows regulation in heterogeneous terrigenous oil reservoirs will align the front of oil displacement by water and, as a consequence, will increase the efficiency of oil recovery from highly watered terrigenous reservoirs due to additional production oil from previously involved areas to the development process.

\section{REFERENCE}

1. Alvarado V. Methods of increasing oil recovery. Planning and application strategies / V. Alvarado, E. Manrik, Falaleev L.B.; edited by A.O. Palia. - Moscow: Premium Engineering LLC, 2011. - 224 p.

2. Altunina L.K. Increase in oil recovery by surfactant compositions / L.K. Altunina, V.A. Kuvshinov. - Novosibirsk: Nauka, 1995. - 198 p.

3. Babalyan G.A. et al. Development of oil fields using surfactants / G.A. Babalyan, B.I. Levi, A.B. Tumasyan, E.M. Khalimov. - M.: Nedra, 1983. - 216 p.

4. Babalyan G.A. Physico-chemical processes in oil production / G.A. Babalyan. - M.: Nedra, 1974. 200 p.

5. Baida A.A. Micellar solutions and microemulsions for enhanced oil recovery / A.A. Baida, S.G. Agaev / Oilfield business. - 2012. -№ 7. p. 37-40.

6. Burdyn T.A. Methods of increasing oil recovery during flooding / T.A. Burdyn, A.T. Gorbunov, L.V. Lyutin, M.L. Surguchev, O.E. Tsynkova. - M.: Nedra, 1983. - 192 p.

7. Gavura V.E. Geology and development of oil and gas-oil fields. - Moscow: VNIIOENG, 1995. - 496 p.

8. Gazizov A.A. Factors of effective development of oil and gas fields / A.A. Gazizov. - Kazan: center of innovative technologies, 2012. - $224 \mathrm{p}$.

9. Himaletdinov R.A. Criteria for the effective application of technologies for leveling the profile of reservoir pick-up in the conditions of development of fields of JSC "Gazprom Neft" / R.A. Khimaletdinov, V.V. Sidorenko, R.N. Fakhretdinov, O.A. Bobylev, G.H. Yakimenko, R.L. Pavlishin / Oil industry. - 2015. № 5. $-78 \mathrm{p}$.

10. Gorbunov A.T. Application of micellar solution rims to increase oil recovery / A.T. Gorbunov, D.P. Zabrodin / Oil industry. - 1976. - Vol. 54. - 43 p.

11. Gray D.R. Composition and properties of drilling agents (washing liquids) / D.R. Gray, G.S. Darley, D.E. Stolyarova. - M.: Nedra, 1985. - 511 p.

12. Gurvich L.M. Multifunctional surfactant compositions in technological operations of oil production / L.M. Gurvich, N.M. Sherstnev. - Moscow: VNIIOENG, 1994. -265 p.
13. Demakhin S.A. Study of the influence of hydrophobizing compounds on water saturation and permeability of the bottom-hole zone of the oil reservoir / S.A. Demakhin, A.G. Demakhin, V.B. Gubanov / Oilfield business. - 2009. №6. -p. 25-28.

14. Zheltov Yu.P. Development of oil fields: Textbook for universities / Yu.P. Zheltov - M.: Nedra, 1998. - 365 p.

15. Ibatullin R.R. Increasing oil recovery at the late stage of field development. Theory. Methods. Practice. I R.R. Ibatullin, N.G. Ibragimov, Sh.F. Takhautdinov, R.S. Khisamov - M.: Nedra - Biznestsentr LLC, 2004. - 292 p.

16. Ibragimov G.Z. Chemical reagents for oil production: worker's Handbook / G.Z. Ibragimov, V.A. Sorokin, N.I. Khisamutdinov. - M.: Nedra, 1986. -240 p.

17. Korolev M.I. Analysis of the experience of using compositions based on surfactants to improve oil recovery of terrigenous reservoirs of the Ural-Volga region / M.K. Rogachev, M.I. Korolev /International Scientific research journal "Internationalresearchjournal". - 2016. - No. 3 (45). - Part 2. - p. 102-104

18. Korolev M. I. Regulation of filtration characteristics of highly watered terrigenous strata using emulsion compositions / M.K. Rogachev, M.I. Korolev / Scientific and technical journal "Petroleum Engineer". 2018. - No. 3, p. 44-49

19. Lenchenkova L.E. Enhancement of oil recovery by physico-chemical methods / L.E. Lenchenkova. M.: Nedra, 1998. - 393 p.

20. Lake L. Basic methods of increasing oil recovery / L. Lake. - Texas-Austin: University Of Texas-Austin, 2005.

21. Mavliev A.R. Development of hydrophobic emulsion composition for underground repair of oil wells / A.R. Mavliev, M.V. Narunov, M.K. Rogachev, D.V. Mardashov / Notes of the Mining Institute. - 2012. - No. 1. - T. 195. - p. 57-60.

22. Muslimov R.H. Development of innovative technologies for the development of oil fields in modern conditions / R.H. Muslimov / Oil. Gas. Innovations. - 2012. -№ 2. p. 30-38.

23. Naugolnov M.V. Rheological and filtration studies of emulsion compositions for use in flow-bending technologies / M.V. Naugolnov, M.K. Rogachev, A.R. Mavliev, D.V. Mardashov /Notes of the Mining Institute. - 2012. - No.1. - Vol. 195. - p. 69-72.

24. Orlov G. A. Application of reverse emulsions in oil production / G.A. Orlov, M.S. Kendis, V.N. Glushchenko. - M.: Nedra, 1991. - 224 p.

25. Podoprigora D., Raupov I. (2018) Research of the influence of polymeric drilling mud on the filtration-capacitive properties of polymictic sandstones. Acta Technica CSAV (CeskoslovenskAkademie Ved) (ISSN: 00017043), 63(4), pp. 537-546. 
26. Rogachev M.K. Development of emulsion compositions for regulation of filtration characteristics of bottom-hole zone of injection wells / M.K. Rogachev, D.V. Mardashov, A.R. Mavliev, K.V. Strizhnev / Oil and Gas business, 2011. - No. 3, - Pp. 180-190.

27. Rogatchev, M.K., Kuznetsova, A.N. Technology of low-permeable polimictic reservoirs water-flooding with surfactant solutions / Innovation-Based Development of the Mineral Resources Sector: Challenges and Prospects - 11th conference of the Russian-German Raw Materials, 2018; p. 161-166, 2019.

28. Strizhnev K.V. Repair and workover operations in wells: Theory and practice / K.V. Strizhnev. - St. Petersburg: "Nedra", 2010. - 560 p.

29. Surguchev M.L. Methods of extraction of residual oil / M.L. Surguchev, A.T. Gorbunov, D.P. Zabrodin. M.: Nedra, 1991. - 346 p.

30. Surguchev M.L. Application of micellar solutions to increase oil recovery / M.L. Surguchev, V.A. Shevtsov, V.V. Surin. - M.: Nedra, 1977. - 175 p.

31. Syrkin A.M. Surface phenomena and disperse systems in the oilfield business: The textbook / A.M. Syrkin, E.M. Movsumzade. - Ufa: Publishing house of USPTU, 2005. - 136 p.

32. Tokarev M.A. Analysis of the effectiveness of the methods of increasing oil recovery at large development sites: Textbook / M.A. Tokarev, E.R. Akhmerova, A.A. Gazizov, I.Z. Denislamov. - Ufa: Publishing house of USPTU, 2001. - $115 \mathrm{p}$.

33. Khisamov R.S. Increase in the coverage of productive strata impact / R.S. Khisamov, A.A. Gazizov, A.Sh. Gazizov. - Moscow: VNIIOENG, 2003. - 564 p.

34. Akinin D.V. et al. Methodology of Selecting Pilot Development Areas for Application of BrightWater ${ }^{\mathrm{TM}}$ Technology //IOR 2013-17th European Symposium on Improved Oil Recovery. - 2013.

35. Crespo F. et al. Development of a Polymer Gel System for Improved Sweep Efficiency and Injection Profile Modification of IOR/EOR Treatments //IPTC 2014: International Petroleum Technology Conference. -2014

36. Dake L.P. Fundamentals of reservoir engineering. Elsevier, 1983.

37. Delamaide E. et al. Chemical EOR in Low Permeability Reservoirs //SPE EOR Conference at Oil and Gas West Asia. - Society of Petroleum Engineers, 2014.

38. Dwarakanath V. et al. Using co-solvents to provide gradients and improve oil recovery during chemical flooding in a light oil reservoir //SPE Symposium on Improved Oil Recovery. - Society of Petroleum Engineers, 2008.
39. El-Karsani K.S.M. et al. Polymer Systems for Water Shutoff and Profile Modification: A Review Over the Last Decade //SPE Journal. - 2014. - T. 19. - №. 01. - C. 135-149.

40. Green D.W., Willhite G.P. Enhanced oil recovery. Richardson, Tex.: Henry L. Doherty Memorial Fund of AIME, Society of Petroleum Engineers, 1998.

41. Haynes A.K. et al. The Successful Implementation of a Novel Polymer EOR Pilot in the Low Permeability Windalia Field //Paper SPE 165253 presented at the SPE Enhanced Oil Recovery Conference. Kuala Lumpur. Malaysia. - 2013. - C.2-4.

42. Hirasaki G. et al. Recent advances in surfactant EOR //SPE Journal. - 2011. - T. 16. - №. 04. - C. 889-907.

43. Iglauer S. et al. Alkyl polyglycoside surfactant-alcohol cosolvent formulations for improved oil recovery //Colloids and Surfaces A: Physicochemical and Engineering Aspects. - 2009. - T. 339. - №. 1-3. - C. 48-59.

44. Johannessen A.M., Spildo K. Enhanced oil recovery (EOR) by combining surfactant with low salinity injection //Energy \& Fuels. - 2013. - T. 27. - №. 10. - C. 5738-5749.

45. Lake L.W. Enhanced oil recovery. - 1989.

46. Latil M. Enhanced oil recovery. - Editions OPHRYS, 1980.

47. Manrique E. et al. Colloidal Dispersion Gels (CDG): Field Projects Review //SPE EOR Conference at Oil and Gas West Asia. - Society of Petroleum Engineers, 2014.

48. Manrique E. et al. EOR field experiences in carbonate reservoirs in the United States //SPE Reservoir Evaluation \& Engineering. - 2007. - T. 10. - №. 06. - C. 667-686.

49. Mitchell J. et al. Monitoring Chemical EOR Processes //SPE Improved Oil Recovery Symposium. - Society of Petroleum Engineers, 2014.

50. Oglesby K. Improved Mobility Control for Carbon Dioxide (CO2) Enhanced Oil Recovery Using Silica-Polymer-Initiator (SPI) Gels. - Impact Technologies LIc, 2014.

51. Sheng J. Modern chemical enhanced oil recovery: theory and practice. - Gulf Professional Publishing, 2010.

52. Stosur G.J. et al. EOR: Past Present and What the Next 25 Years May Bring //SPE International Improved Oil Recovery Conference in Asia Pacific. Society of Petroleum Engineers, 2003.

53. Taber J.J. et al. EOR screening criteria revisited-Part 1: Introduction to screening criteria and enhanced recovery field projects //SPE Reservoir Engineering. - 1997. - T. 12. - №. 03. - C. 189-198. 
54. Tagavifar M. et al. Measurement of microemulsion viscosity and its implications for chemical enhanced oil recovery //SPE Journal. - 2018. - T. 23. - №. 01. - C. 66-83.

55. Tagavifar M. et al. Controlling the composition, phase volume, and viscosity of microemulsions with cosolvent //Fuel. - 2018. - T. 211. - C. 214-222.

56. Thrasher D.R. et al. First Application in Russia of Bright Water ${ }^{\mathrm{TM}}$ Chemical for Waterflood Sweep Improvement in the Samotlor Field //IOR 2013-From Fundamental Science to Deployment. - 2013.

57. Wang D. et al. Novel surfactants that attain ultra-low interfacial tension between oil and high salinity formation water without adding alkali, salts, co-surfactants, alcohols and solvents //SPE EOR Conference at Oil \& Gas West Asia. - Society of Petroleum Engineers, 2010.

58. Zaitoun A. et al. Shear stability of EOR polymers // SPE J. - 2012. - T. 17. - №. 2. - C. 335-339.
59. Zhang Y. et al. Improved Heavy Oil Recovery by CO2 Injection Augmented with Chemicals //International Oil and Gas Conference and Exhibition in China. - Society of Petroleum Engineers, 2010.

60. Zhao P. et al. Development of high-performance surfactants for difficult oils //SPE Symposium on Improved Oil Recovery. - Society of Petroleum Engineers, 2008.

61. Jafarpour, H., Moghadasi, J., Khormali, A., Petrakov, D. G., \& Ashena, R. (2019). Increasing the stimulation efficiency of heterogeneous carbonate reservoirs by developing a multi-bached acid system. Journal of Petroleum Science and Engineering, 172, 50-59. doi:10.1016/j.petrol.2018.09.034

62. Khormali, A., Petrakov, D. G., \& Jafarpour, H. (2019). Experimental and theoretical investigations of inorganic salt precipitation and control for oil reservoirs. Paper presented at the Innovation-Based Development of the Mineral Resources Sector: Challenges and Prospects - 11th Conference of the Russian-German Raw Materials, 2018, 155-160. 